\title{
Success in learning similar-sounding words predicts vocabulary depth above and beyond vocabulary breadth
}

\author{
Merel M. VAN GOCH ${ }^{1,2,3 *}$, Ludo VERHOEVEN ${ }^{1}$, and James M. MCQUEEN ${ }^{2,4}$ \\ ${ }^{1}$ Radboud University, Behavioural Science Institute, Nijmegen, the Netherlands, ${ }^{2}$ Radboud University, \\ Donders Institute for Brain, Cognition and Behaviour, Nijmegen, the Netherlands, ${ }^{3}$ Utrecht University, \\ Institute for Cultural Inquiry, Utrecht, the Netherlands, and ${ }^{4}$ Max Planck Institute for Psycholinguistics, \\ Nijmegen, the Netherlands \\ ${ }^{*}$ Corresponding author: Merel M. van Goch is now working at Liberal Arts and Sciences, Utrecht \\ University. Merel M. van Goch, Utrecht University, Janskerkhof 13, 3512 BL Utrecht, the Netherlands; \\ E-mail: m.m.vangoch@uu.nl; phone: 0031302538308
}

(Received 8 September 2015; revised 17 September 2017; accepted 18 July 2018; first published online 21 September 2018)

\begin{abstract}
In lexical development, the specificity of phonological representations is important. The ability to build phonologically specific lexical representations predicts the number of words a child knows (vocabulary breadth), but it is not clear if it also fosters how well words are known (vocabulary depth). Sixty-six children were studied in kindergarten (age $5 ; 7$ ) and first grade (age 6;8). The predictive value of the ability to learn phonologically similar new words, phoneme discrimination ability, and phonological awareness on vocabulary breadth and depth were assessed using hierarchical regression. Word learning explained unique variance in kindergarten and first-grade vocabulary depth, over the other phonological factors. It did not explain unique variance in vocabulary breadth. Furthermore, even after controlling for kindergarten vocabulary breadth, kindergarten word learning still explained unique variance in first-grade vocabulary depth. Skill in learning phonologically similar words appears to predict knowledge children have about what words mean.
\end{abstract}

Keywords: word learning; vocabulary depth; vocabulary breadth; phonological development; lexical development

Vocabulary is an important component of reading ability and academic success (Biemiller, 2006; Scarborough, 2005; Stoel-Gammon, 2011; Storch \& Whitehurst, 2002; Verhoeven, Reitsma, \& Siegel, 2011), but children's vocabulary knowledge varies significantly at the beginning of elementary school (Hart \& Risley, 1995), and this variance grows (Biemiller \& Slonim, 2001). This research has mainly focused on vocabulary breadth: the number of words children know. Less work has been done on vocabulary depth: how well children know what words mean. In this study, we tracked phonological and lexical development of Dutch children in kindergarten and

(c) Cambridge University Press 2018 
first grade. We asked whether skill in learning phonologically similar words is predictive not only of vocabulary breadth but also of knowledge about the meaning of words, that is, vocabulary depth.

Word learning should not be seen as "an all-or-none proposition" (Beck, McKeown, \& Kucan, 2002); rather, word learning exists on an incremental continuum ranging from no knowledge, via recognition and rough or partial knowledge, to in-depth knowledge about a lexical item (Beck et al., 2002; Nagy \& Scott, 2000; Schwanenflugel, Stahl, \& McFalls, 1997; Vermeer, 2001). Vocabulary breadth and depth thus have different developmental trajectories and relations to other early literacy skills (Anderson \& Freebody, 1981; Ouellette, 2006; Read, 2004; Schmitt, 2014; Vermeer, 2001). For example, Ouellette (2006) found that, in fourth-grade students, receptive vocabulary breadth predicted word decoding, expressive vocabulary breadth predicted visual word recognition, and vocabulary depth predicted reading comprehension. Vocabulary breadth was measured by asking participants which of multiple presented pictures corresponds to an auditorily presented word, whereas vocabulary depth was assessed by asking participants to describe or define a given word. Breadth and depth, while related aspects of vocabulary, are nonetheless different constructs, not only because they have different developmental trajectories and are measured in different ways but also because of a fundamental distinction: knowing how many words are in a child's lexicon cannot determine how much they know about the meanings of particular words, nor vice versa.

The richness and specificity of phonological representations plays a crucial role in several accounts of the development of vocabulary breadth and depth. Note that these accounts are not directly tested here, but they are relevant to the rationale of this study. The LEXICAL Restructuring model (Metsala \& Walley, 1998) suggests that representations gradually develop from more global to more specified, and that this lexical restructuring is related to vocabulary breadth: increasing vocabulary size leads to increasingly segmented representations. More recently, however, the relationship between representations and vocabulary size has been suggested to be bi-directional or mutually dependent (Beckman, Munson, \& Edwards, 2007; Munson, Edwards, \& Beckman, 2011). Underspecified representations are also the key feature of the PHONOLOGICAL REPRESENTATIONS HYPOTHESIS (Hulme \& Snowling, 2009; Swan \& Goswami, 1997), which proposes that children with poorer early literacy skills (i.e., reading and phonological awareness) have a basic deficit in how they represent the sound structures of words. According to the LEXICAL QUALITY HYPOTHESIS (Perfetti \& Hart, 2002), words can only be accessed and used adequately if their form (phonology and orthography) and meaning are represented with sufficient precision, flexibility, and quality. Thus, the development of vocabulary breadth depends on the development of and access to phonological representations in the mental lexicon.

The question that follows, then, is what aspects of phonological development are related to the development of vocabulary depth. Phonological factors that likely influence vocabulary development are perceptual discrimination skill, phonological awareness, and the ability to learn phonologically similar new words. Perceptual abilities are predictive of vocabulary. For example, 12-month-olds who were better at segmenting speech had a larger vocabulary at 24 months and scored higher on vocabulary and other language measures in preschool (Newman, Ratner, Jusczyk, Jusczyk, \& Dow, 2006). A study with Dutch children showed that speech perception abilities at 7 months of age were associated with vocabulary and language production at age three (Kooijman, Junge, Johnson, Hagoort, \& Cutler, 2013). However, in a 
very similar study, Junge and Cutler (2014) did not find a relationship between infant speech perception skill and vocabulary at age five. Nevertheless, relationships between phoneme discrimination ability and literacy have been found in elementary school children (Serniclaes, Van Heghe, Mousty, Carré, \& Sprenger-Charolles, 2004). Therefore, it is important to control for the ability to discriminate phonemes in older children, for example through perception tasks in which they are asked to indicate whether two words sound the same.

Phonological awareness is also closely related to vocabulary (Bowey \& Patel, 1988; Chaney, 1992; Lonigan, Burgess, \& Anthony, 2000; Metsala \& Walley, 1998). This metalinguistic skill involves being able to consciously reflect upon and manipulate speech sounds. Since phonological awareness constitutes several subskills, different phonological awareness tasks exist, including rhyming, blending, and deletion tasks. Most research has focused on vocabulary as a predictor of phonological awareness (Metsala, 1999; Wagner, Torgesen, \& Rashotte, 1994); for example, Lonigan et al. (2000) found that preschoolers' vocabulary skills predict their phonological awareness sixteen months later. However, this relationship is probably bi-directional (Ehri, 2005), in that awareness of speech sounds aids discriminating between words and hence fosters word learning.

Finally, the ability to learn phonologically similar new words is also related to phonological awareness and vocabulary size (Elbro, Borstrøm, \& Petersen, 1998; Janssen, Segers, McQueen, \& Verhoeven, 2015; van Goch, McQueen, \& Verhoeven, 2014; van Goch, Verhoeven, \& McQueen, 2017). Kindergartners who are good at learning similar-sounding words through a word-learning game know more words. In the word-learning game used to assess this skill, children are taught real, but previously unknown, words that sound similar (van Goch et al., 2014). Success depends on the ability to discriminate similar-sounding words and on pairing the acoustic representations to specific pictures. Being good in learning new words logically leads to a larger vocabulary, because more new representations can be learned and stored. These three phonological skills all tap into different aspects of phonological representations (i.e., perception, metalinguistic awareness, learning) but are related to each other. Therefore, it is necessary to incorporate measures of all of them when studying the relationship between phonological and lexical development.

In the current study, we asked how Dutch children's vocabulary in the second year of kindergarten and in first grade is influenced by phonological skills. At this age children learn words auditorily, in contrast to when they are older and can learn words via print (Biemiller, 2006; Graves, 1987). We investigated how phonological factors predict vocabulary breadth and depth, including analyses controlling, in turn, for vocabulary depth and breadth, given our assumption that these are separate constructs. Most studies investigating the relationship between phonological and lexical development have been merely correlational, or have focused on the role of lexical development in phonological development. Here, multiple hierarchical regression analyses assessed how phoneme discrimination skill, phonological awareness, and the ability to learn phonologically similar words predicted vocabulary. We hypothesized that phoneme discrimination plays a role in vocabulary development because, to be able to learn words, children need to be able to categorize acoustic information and discriminate between phonemes. Phonological awareness was hypothesized to play a role because metalinguistic awareness of speech sounds aids word learning. Success in learning words that sound similar was predicted to play a crucial role because it fosters the number of words children know and likely also how well they know them, due to 
mappings between phonological and semantic information of representations in the mental lexicon.

\section{Method \\ Participants}

Sixty-six randomly selected monolingual speakers of Dutch (38 boys) - none of them diagnosed with developmental or language-related problems, according to their parents and/or teachers - were assessed in the second year of kindergarten (K2; mean age $5 ; 7$; range \pm 4 months) and in first grade ( $\mathrm{Gl}$; mean age $6: 8)$. In the Netherlands, children typically attend two years of kindergarten, during which they do not yet receive explicit reading instruction. Formal reading education commences in first grade. Children's age did not correlate significantly with their scores on any of the measures.

\section{Materials}

\section{Phonological factors}

Word Learning. The ability to learn phonologically similar new words was measured using the word-learning game developed by van Goch et al. (2014; Cronbach's alpha $=.77$ ). Children learned pairs of new lexical representations that phonologically differed minimally from each other, by means of pictures and auditory stimuli. Words were selected to be unknown to children in kindergarten (e.g., they did not appear in a list of basic vocabulary in kindergarten; Mulder, Timman, \& Verhallen, 2009). The stimuli were grouped into 24 quadruplets of real monosyllabic Dutch words (see Table 1). Each quadruplet consisted of two unfamiliar target words that differed on one acoustic-phonetic feature (e.g., raap 'turnip' and raat 'honeycomb' differ in place of articulation), an unfamiliar control word (e.g., raaf 'raven'), and a familiar control word (e.g., raam 'window'). Both control words differed on two acoustic-phonetic features with both target words. Contrast Type (manner of articulation, place of articulation, voicing) and Contrast Position (initial versus final phoneme) were manipulated. On every trial, four pictures were shown (two experimental stimuli and two highly familiar filler pictures), and the target question was presented auditorily, containing only one of two target words of a stimulus quadruplet (e.g., "What do you think is a raap?"). Children had to discriminate between the new, similar-sounding words and link the acoustic information to the corresponding pictures. Task difficulty increased gradually during the task: in the first part of the task the familiar control words were paired with the target words and there was a two-feature difference between the target and control words, whereas in the second part the unfamiliar control words were used and there was a one-feature difference. Positive feedback was provided after correct trials; no negative feedback was ever given. The task consisted of 134 trials, was never terminated prematurely, and took 15 minutes on average. The score was the percentage of correct trials overall.

Phoneme Discrimination. In the standardized Phoneme Discrimination subtask of the Diagnostic Test for Language and Literacy Problems (Cronbach's alpha =.82; Verhoeven, 2005) children were asked if two auditorily presented words were the 
Table 1. Examples of Stimulus Quadruplets Used in the Word Learning Task

\begin{tabular}{llllll}
\hline $\begin{array}{l}\text { Unfamiliar } \\
\text { Target A }\end{array}$ & $\begin{array}{l}\text { Unfamiliar } \\
\text { Target B }\end{array}$ & $\begin{array}{l}\text { Unfamiliar } \\
\text { Control }\end{array}$ & $\begin{array}{l}\text { Familiar } \\
\text { Control }\end{array}$ & $\begin{array}{l}\text { Contrast } \\
\text { Type }\end{array}$ & $\begin{array}{l}\text { Contrast } \\
\text { Position }\end{array}$ \\
\hline luit & ruit & kuit & huid & Manner & Initial \\
\hline bar & dar & war & kar & Place & Initial \\
\hline pas & bas & gas & jas & Voice & Initial \\
\hline pol & pon & pos & pop & Manner & Final \\
\hline raap & raat & raaf & raam & Place & Final \\
\hline
\end{tabular}

same. All stimuli were monosyllabic, high-frequency words. The words in each pair of stimuli were either the same, or they differed on manner of articulation, place of articulation, or voicing. The score was the percentage of correct trials.

Phonological Awareness. In all three subtasks of the standardized Diagnostic Instrument for Emergent Literacy (Cronbach's alpha $=>.90$; Vloedgraven, Keuning, \& Verhoeven, 2009), children were presented with three response alternatives (visually on a computer screen and auditorily over headphones) and the experimental question (auditorily). In the RHyme Awareness task, children selected the response alternative that rhymed with the target stimulus ("Hoed, bal, peer; wat rijmt op beer?" 'Hat, ball, pear; what rhymes with bear?'). In the PHONEME SYNTHESIs task, children combined the separate phonemes of the auditory target into a word and selected the response alternative that depicted that word ("Hoed, bal, peer; /b/ - /a/ - /l/" 'Hat, ball, pear; /b/-/a/ - /l'). In the Phoneme Identification task, children selected the response alternative whose name started with the same phoneme as the auditory target stimulus ("Hoed, bal, peer; de $\mathrm{b}$ van beer" 'Hat, ball, pear; the b of bear'). Since the scores for the individual subtasks correlated significantly (Pearson's $r$ ranged between .29 and .57) and it is common to collapse the scores for these Phonological Awareness subtasks, the score for Phonological Awareness was the average percentage of correct trials across the three subtasks.

\section{Vocabulary measures}

Breadth. Using the Receptive Vocabulary task of the standardized Dutch Language Test for Children (Cronbach's alpha > 0.95; Verhoeven \& Vermeer, 2006), four response alternatives were visually presented to the children. Given an auditory target stimulus, the children were asked to select the picture of the word that was named. The task consisted of 96 trials and was discontinued if five consecutive errors were made. The score on this task was the number of correct trials.

Depth. Using the Word Description task of the same standardized Dutch Language Test (Cronbach's alpha > .91), children were asked to define a given spoken word (e.g., 'battery'). None of the words in this task appear in the Receptive Vocabulary task. Per trial, children could score two, one, or zero points, depending on the extensiveness of their answer. Zero points were given in case of incorrect or null answers. One point was administered if the child partly defined the target word (e.g., 'a battery goes in a remote control'). Two points were given if the child completely 
defined the target word (e.g., 'a battery provides energy to a remote control'). The task consisted of 45 trials; the maximum score was 90 . The task was discontinued if zero points were given in four consecutive items. The score was the sum of points for all trials.

\section{Procedure}

All children were tested individually in a quiet room in their school. The tests were administered in a fixed order. Vocabulary Breadth and Depth were administered in $\mathrm{K} 2$ and $\mathrm{G} 1$; the other tasks were administered only in $\mathrm{K} 2$.

\section{Data analysis}

We first evaluated the descriptive statistics and correlations. Then multiple hierarchical regression analyses were carried out, in three phases (see Table 2). The first phase assessed the predictive value of the three phonological factors. The next phase controlled in turn for one of the Vocabulary measures, and in the last, most conservative phase, we controlled for performance on both Vocabulary measures.

\section{Results}

\section{Descriptive statistics and correlations}

Group performance was above chance level on all measures for which this was possible to assess (Table 3). Four children (6\%) scored below chance on Word Learning, four children scored below chance on Phoneme Discrimination, and zero children scored below chance on Phonological Awareness. To account for natural classroom variation, these children were not dropped from the analyses.

The correlations amongst the phonological factors were significant, but weak (Table 4), indicating that multicollinearity was unlikely to be a problem for the regression analyses. All correlations between the two measures of vocabulary were moderate to strong on both occasions (K2 versus G1). Word Learning correlated moderately with both vocabulary measures at both times, except for G1 Vocabulary Breadth. Phonological Awareness correlated weakly to moderately with both vocabulary measures at both times; Phoneme Discrimination only correlated with K2 Vocabulary Breadth.

\section{Hierarchical regression analyses \\ Phase 1}

The first hierarchical regression analyses were carried out to assess how performance on the phonological factors in the second year of kindergarten predicts performance on Vocabulary Breadth and Depth in the second year of kindergarten and first grade (Table 5). In the first step, K2 Phoneme Discrimination was entered. This model was only a significant predictor for K2 Vocabulary Breadth, for which it explained $6.4 \%$ of the variance. In the second step, K2 Phonological Awareness was added. Now, the model was a significant predictor for all outcome variables, except for G1 Vocabulary Depth. It explained $16.5 \%$ of the variance in K2 Vocabulary Breadth, $7.0 \%$ of variance in K2 Vocabulary Depth, and $8.1 \%$ of variance in G1 Vocabulary 
Table 2. Different Phases of Data Analysis

\begin{tabular}{lll}
\hline Phase & Predictors & Dependent variable(s) \\
\hline 1.1 & Phonological factors K2 & Vocabulary Breadth K2 + G1 \\
\hline 1.2 & Phonological factors K2 & Vocabulary Depth K2 + G1 \\
\hline 2.1 & Vocabulary Depth + Phonological factors K2 & Vocabulary Breadth K2+G1 \\
\hline 2.2 & Vocabulary Breadth + Phonological factors K2 & Vocabulary Depth K2 + G1 \\
\hline 3.1 & $\begin{array}{c}\text { Vocabulary Breadth + Vocabulary Depth + } \\
\text { Phonological factors K2 }\end{array}$ & Vocabulary Breadth G1 \\
\hline 3.2 & $\begin{array}{c}\text { Vocabulary Depth + Vocabulary Breadth }+ \\
\text { Phonological factors K2 }\end{array}$ & Vocabulary Depth G1 \\
\hline
\end{tabular}

Table 3. Descriptive Statistics $(n=66)$

\begin{tabular}{llll}
\hline & & Mean (SD) & Chance level \\
\hline Kindergarten 2 & Phoneme Discrimination & $78.03 \%^{\star}(14.604)$ & $50 \%$ \\
\hline & Phonological Awareness & $62.05 \%^{\star}(15.545)$ & $33 \%$ \\
\hline & Word Learning & $47.54 \%^{\star}(14.266)$ & $25 \%$ \\
\hline & Vocabulary Breadth & $60.38(11.025)$ & $\mathrm{n} / \mathrm{a}$ \\
\hline Vocabulary Depth & $15.35(5.702)$ & $\mathrm{n} / \mathrm{a}$ \\
\hline & Vocabulary Breadth & $77.85(7.592)$ & $\mathrm{n} / \mathrm{a}$ \\
\hline
\end{tabular}

Note. * Performance significantly above chance level (if possible to assess).

Table 4. Correlations between Variables of Children's Performance $(n=66)$

\begin{tabular}{|c|c|c|c|c|c|c|c|c|}
\hline & & 1 & 2 & 3 & 4 & 5 & 6 & 7 \\
\hline \multirow[t]{5}{*}{ Kindergarten 2} & 1. Phoneme Discrimination & - & & & & & & \\
\hline & 2. Phonological Awareness & $.292^{\star}$ & - & & & & & \\
\hline & 3. Word Learning & $.270^{\star}$ & $.297^{\star}$ & - & & & & \\
\hline & 4. Vocabulary Breadth & $.280^{\star}$ & $.404^{\star \star}$ & $.366^{\star *}$ & - & & & \\
\hline & 5. Vocabulary Depth & .112 & $.313^{*}$ & $.372^{\star \star}$ & $.471^{\star \star}$ & - & & \\
\hline \multirow[t]{2}{*}{ Grade 1} & 6. Vocabulary Breadth & .196 & $.312^{\star}$ & .177 & $.655^{\star \star}$ & $.418^{\star \star}$ & - & \\
\hline & 7. Vocabulary Depth & .023 & $.250^{*}$ & $.341^{\star \star}$ & $.402^{\star \star}$ & $.642^{\star \star}$ & $.343^{\star *}$ & - \\
\hline
\end{tabular}

Note. ${ }^{\star} p<.05 ;{ }^{\star \star} p<.01$.

Breadth. In the third step of the regression analysis, K2 Word Learning was added. This final model was significant for K2 and G1 Vocabulary Depth, but not for K2 and G1 Vocabulary Breadth. The total variance explained by the model as a whole was $14.5 \%$ for K2 Vocabulary Depth and $10.9 \%$ for G1 Vocabulary Depth. The 
Table 5. Effects of Phoneme Discrimination, Phonological Awareness and Word Learning in the Second Year of Kindergarten on Vocabulary Breadth and Vocabulary Depth in the Second Year of Kindergarten and in First Grade $(n=66)$

\begin{tabular}{|c|c|c|c|c|c|c|c|c|c|c|c|c|}
\hline & \multicolumn{6}{|c|}{ Kindergarten 2} & \multicolumn{6}{|c|}{ Grade 1} \\
\hline & \multicolumn{3}{|c|}{ Vocabulary Breadth } & \multicolumn{3}{|c|}{ Vocabulary Depth } & \multicolumn{3}{|c|}{ Vocabulary Breadth } & \multicolumn{3}{|c|}{ Vocabulary Depth } \\
\hline & $R_{a d j}^{2}$ & $\Delta R^{2}$ & $\beta$ & $R_{a d j}^{2}$ & $\Delta R^{2}$ & $\beta$ & $R_{a d j}^{2}$ & $\Delta R^{2}$ & $\beta$ & $R_{a d j}^{2}$ & $\Delta R^{2}$ & $\beta$ \\
\hline Step 1 & $0.064^{*}$ & - & & -0.003 & - & & 0.023 & - & & -0.015 & - & \\
\hline Phoneme Discrimination & & & $0.280^{\star}$ & & & 0.112 & & & 0.196 & & & 0.023 \\
\hline Step 2 & $0.165^{\star \star \star}$ & $.113^{\star \star}$ & & $0.070^{\star}$ & $.086^{\star}$ & & $0.081^{*}$ & $.071^{\star}$ & & 0.035 & $.065^{*}$ & \\
\hline Phoneme Discrimination & & & 0.175 & & & 0.022 & & & 0.114 & & & -0.053 \\
\hline Phonological Awareness & & & $0.352^{\star \star}$ & & & $0.307^{\star}$ & & & $0.279^{\star}$ & & & $0.265^{\star}$ \\
\hline Step 3 & $.202^{\star \star \star}$ & $.048 !$ & & $.145^{\star \star}$ & $.086^{\star}$ & & $.071 !$ & .005 & & $.109^{\star}$ & $.086^{\star}$ & \\
\hline Phoneme Discrimination & & & 0.131 & & & -0.041 & & & 0.100 & & & -0.116 \\
\hline Phonological Awareness & & & $0.287^{\star}$ & & & 0.232 & & & $0.262^{*}$ & & & 0.186 \\
\hline Word Learning & & & $0.237 !$ & & & $0.314^{\star}$ & & & 0.072 & & & $0.315^{\star}$ \\
\hline
\end{tabular}

Notes. ! $<.06 ;{ }^{\star} p \leqslant .05 ;{ }^{\star \star} p \leqslant .01 ;{ }^{\star \star \star} p \leqslant .001$ 
introduction of $\mathrm{K} 2$ Word Learning explained additional 8.6\% variance in Vocabulary Depth in both K2 and G1.

\section{Phase 2}

The next analyses assessed how performance on the Vocabulary Depth task and on the phonological tasks in the second year of kindergarten predicted performance on Vocabulary Breadth in the second year of kindergarten and first grade (Table 6). The first predictor was K2 Vocabulary Depth, which was significant. It explained 20.9\% of the variance in Vocabulary Breadth in $\mathrm{K} 2$ and $16.2 \%$ in G1. The next added predictor, Phoneme Discrimination, was a significant predictor for Vocabulary Breadth in K2, but not in G1. For K2 Vocabulary Breadth, the model was significantly better than the model with just Vocabulary Depth; it now explained $25.1 \%$ of the variance. Next, Phonological Awareness was added. This did not significantly improve the model for G1 Vocabulary Breadth, but it did for K2 Vocabulary Breadth. The new model now explained 28.6\% variance. Adding Word Learning, in the end, did not significantly improve the models for K2 or G1 Vocabulary Breadth.

Hierarchical regression analyses were then carried out to assess how performance on the Vocabulary Breadth task and on the phonological tasks in the second year of kindergarten predicted performance on Vocabulary Depth in the second year of kindergarten and first grade (Table 7). K2 Vocabulary Breadth was first added as a predictor and proved to be significant, explaining $20.9 \%$ of the variance in $\mathrm{K} 2$ and $14.8 \%$ of the variance in G1 Vocabulary Depth. When Phoneme Discrimination was added as a predictor, the model was significant, explaining $19.7 \%$ of variance in $\mathrm{K} 2$ Vocabulary Depth and $14.2 \%$ of variance in G1, but adding Phoneme Discrimination did not explain significantly more variance. When Phonological Awareness was added, it did not explain significantly more variance, but the model remained a significant predictor of K2 (20.7\%) and G1 Vocabulary Depth (14.1\%). In the fourth step, Word Learning was added. Although the percentage of explained variance increased, this did not lead to significantly more explained variance in $\mathrm{K} 2$ Vocabulary Depth (23.6\%). Adding Word Learning did improve the model significantly for G1 Vocabulary Depth, explaining $18.3 \%$ of the variance. In the final model, K2 Vocabulary Breadth and Word Learning were significant predictor variables of G1 Vocabulary Depth.

\section{Phase 3}

The next analysis assessed whether K2 Vocabulary Depth and the phonological factors explained variance in performance on G1 Vocabulary Breadth, beyond K2 Vocabulary Breadth. This was not the case: K2 Vocabulary Breadth explained $42 \%$ of the variance in G1 Vocabulary Breadth and no further predictor contributed significantly. Last, we analysed whether K2 Vocabulary Breadth and phonological factors explained variance in G1 Vocabulary Depth beyond K2 Vocabulary Depth. This proved also not to be the case: K2 Vocabulary Depth explained $40.7 \%$ of the variance in G1 Vocabulary Depth and no other predictor added significantly more variance.

\section{Discussion}

This study investigated how performance on three phonological factors - phoneme discrimination skill, phonological awareness, and the ability to learn phonologically 
Table 6. Effects of Vocabulary Depth, Phoneme Discrimination, Phonological Awareness and Word Learning in the Second Year of Kindergarten on Vocabulary Breadth in the Second Year of Kindergarten and in First Grade $(n=66)$

\begin{tabular}{|c|c|c|c|c|c|c|}
\hline & \multicolumn{3}{|c|}{$\begin{array}{c}\text { Kindergarten } 2 \\
\text { Vocabulary Breadth }\end{array}$} & \multicolumn{3}{|c|}{$\begin{array}{c}\text { Grade } 1 \\
\text { Vocabulary Breadth }\end{array}$} \\
\hline & $R_{a d j}^{2}$ & $\Delta R^{2}$ & $\beta$ & $R_{a d j}^{2}$ & $\Delta R^{2}$ & $\beta$ \\
\hline Step 1 & $.209^{\star \star \star}$ & - & & $.162^{\star \star \star}$ & - & \\
\hline Vocabulary Depth & & & $0.471^{\star \star \star}$ & & & $0.418^{* * *}$ \\
\hline Step 2 & $.251^{\star \star *}$ & $.053^{*}$ & & $.172^{\star \star \star}$ & .022 & \\
\hline Vocabulary Depth & & & $0.445^{\star \star \star}$ & & & $0.401^{\star \star \star}$ \\
\hline Phoneme Discrimination & & & $0.231^{*}$ & & & 0.151 \\
\hline Step 3 & $.286^{\star * *}$ & $.045^{*}$ & & $.184^{\star \star \star}$ & .024 & \\
\hline Vocabulary Depth & & & $0.378^{\star \star \star}$ & & & $0.352^{\star \star}$ \\
\hline Phoneme Discrimination & & & 0.169 & & & 0.106 \\
\hline Phonological Awareness & & & $0.233^{*}$ & & & 0.171 \\
\hline Step 4 & $.289^{\star \star *}$ & .014 & & $.172^{\star \star}$ & .001 & \\
\hline Vocabulary Depth & & & $0.338^{\star \star}$ & & & $0.365^{\star \star}$ \\
\hline Phoneme Discrimination & & & 0.145 & & & 0.115 \\
\hline Phonological Awareness & & & 0.209 & & & 0.177 \\
\hline Word Learning & & & 0.133 & & & -0.042 \\
\hline
\end{tabular}

Notes. ${ }^{\star} p \leqslant .05 ;{ }^{\star \star} p \leqslant .01 ;{ }^{\star \star *} p \leqslant .001$.

similar new words - predicted vocabulary breadth and depth. The most important finding was that first-grade vocabulary depth was predicted by the ability to learn phonologically similar new words in kindergarten, even when controlling for how many words children knew in kindergarten. In addition, kindergarten vocabulary breadth was predicted by kindergarten phonological awareness, even when controlling for kindergarten vocabulary depth.

The word-learning task that we used to assess the ability to learn phonologically similar new words was designed to teach children new words that phonologically differ minimally from each other. It consists of a phonological and a semantic word-learning component, which interact with each other. The semantic component involves the link between sound and meaning: children must link the particular speech sound sequence (the spoken word) to a particular meaning (the picture). The phonological component involves the ability to discriminate between speech sounds that differ minimally from each other and to use those discriminations at the lexical level. Performance on the word-learning task was related to both phonological and semantic performance. Individual differences on the task correlated with 
Table 7. Effects of Vocabulary Breadth, Phoneme Discrimination, Phonological Awareness and Word Learning in the Second Year of Kindergarten on Vocabulary Depth in the Second Year of Kindergarten and in First Grade $(n=66)$

\begin{tabular}{|c|c|c|c|c|c|c|}
\hline & \multicolumn{3}{|c|}{$\begin{array}{l}\text { Kindergarten } 2 \\
\text { Vocabulary Depth }\end{array}$} & \multicolumn{3}{|c|}{$\begin{array}{c}\text { Grade } 1 \\
\text { Vocabulary Depth }\end{array}$} \\
\hline & $R_{a d j}^{2}$ & $\Delta R^{2}$ & $\beta$ & $R_{a d j}^{2}$ & $\Delta R^{2}$ & $\beta$ \\
\hline Step 1 & $.209^{\star \star \star}$ & - & & $.148^{\star \star \star}$ & - & \\
\hline Vocabulary Breadth & & & $0.471^{\star \star \star}$ & & & $0.402^{\star \star \star}$ \\
\hline Step 2 & $.197^{\star \star \star}$ & .001 & & $.142^{\star \star}$ & .008 & \\
\hline Vocabulary Breadth & & & $0.477^{\star \star \star}$ & & & $0.428^{\star \star \star}$ \\
\hline Phoneme Discrimination & & & -0.023 & & & -0.095 \\
\hline Step 3 & $.207^{\star \star}$ & .022 & & $.141^{\star \star}$ & .012 & \\
\hline Vocabulary Breadth & & & $0.419^{\star \star}$ & & & $0.384^{\star \star}$ \\
\hline Phoneme Discrimination & & & -0.057 & & & -0.119 \\
\hline Phonological Awareness & & & 0.167 & & & 0.125 \\
\hline Step 4 & $.236^{\star \star \star}$ & .040 & & $.183^{\star \star}$ & $.053^{\star}$ & \\
\hline Vocabulary Breadth & & & $0.363^{*}$ & & & $0.321^{*}$ \\
\hline Phoneme Discrimination & & & -0.088 & & & -0.156 \\
\hline Phonological Awareness & & & 0.126 & & & 0.074 \\
\hline Word Learning & & & 0.222 & & & $0.257^{\star}$ \\
\hline
\end{tabular}

Notes. ${ }^{\star} p \leqslant .05 ;{ }^{\star \star} p \leqslant .01 ;{ }^{\star \star \star} p \leqslant .001$.

phonological awareness (as also in Janssen et al., 2015; van Goch et al., 2014; van Goch et al., 2017), but did not predict vocabulary breadth more than phonological awareness. Thus, it did not add significantly more variance to the prediction of vocabulary breadth beyond phonological awareness. On the other hand, the word-learning task did add significantly more variance to the prediction of vocabulary depth. It can thus be assumed that when word-form learning becomes easier, children have more resources and/or memory left to focus on and learn the meaning of the new words. Another possibility is that having phonological labels which are clearer and more distinct makes it easier to tie meaning to form. Thus, good word learners either can free up resources to learn more words and/or can learn more about those words. These explanations are not mutually exclusive. Our results are in line with previous research showing that the specificity of phonological representations is related to phonological awareness and vocabulary (Elbro et al., 1998; Elbro, Nielsen, \& Petersen, 1994; Janssen et al., 2015; van Goch et al., 2014; van Goch et al., 2017) and with theories that highlight the importance of detailed phonological representations in early literacy (Hulme \& Snowling, 2009; Metsala \& Walley, 1998; 
Perfetti \& Hart, 2002), suggesting at least a reciprocal relation between phonological representations and vocabulary (Beckman et al., 2007; Munson et al., 2011).

The finding that the ability to learn phonologically similar new words did not explain unique variance in vocabulary breadth over phoneme discrimination and phonological awareness was unexpected, based on previous research (van Goch et al., 2017). However, the children in the former study were in the first year of kindergarten, whereas the current sample was assessed in the second year of kindergarten and in first grade. It is highly likely that the inter-relations between phonological factors and their predictive strength differ at different time-points. It thus appears that the ability to learn similar-sounding words is related to vocabulary breadth in the short term and to vocabulary depth in the longer term.

Phonological awareness predicted vocabulary breadth in kindergarten and in first grade. Most research on the relation between vocabulary and phonological awareness at this point in development suggests that vocabulary predicts phonological awareness (Metsala, 1999; Wagner et al., 1994). This study shows that phonological awareness also explains unique variance in lexical development, both in the numbers of words children know and in how well they know the meaning of words. Explicit awareness of and access to phonemes, and the ability to consciously manipulate them, thus fosters vocabulary development.

Phoneme discrimination turned out not to be an important predictor for vocabulary breadth or depth. Categorical perception of phonemes thus did play a role in lexical development, but was not as important as phonological awareness. Phoneme discrimination might be more important earlier in lexical development (Junge \& Cutler, 2014; Kooijman et al., 2013; Newman et al., 2006).

The differential results for vocabulary breadth and vocabulary depth underline the need to view these factors as distinct: they have different developmental trajectories. The influence of phonological factors changes over time for each vocabulary measure. The extra analyses controlling for vocabulary highlighted this. The development of vocabulary breadth seems to be mostly driven by perceptual and metalinguistic phonological factors, whereas the development of vocabulary depth seems to be mostly driven by the lexicon and the quality of lexical representations. In language education, attention should be paid to both aspects of vocabulary.

Previous correlational and longitudinal studies have shown that vocabulary is fairly stable during elementary school (e.g., Verhoeven, Van Leeuwe, \& Vermeer, 2011). The current study showed that phonological awareness and the ability to learn phonologically similar new words drive vocabulary development before the start of elementary school. In kindergarten, the current results could inform assessment and intervention of deficits: teaching new similar-sounding words might not only benefit how many words children know, but also how well they know them. Although we only included one measure of each construct at each time-point, these results can inform classroom teaching. Future studies should include multiple measurements of all relevant constructs and should include a larger sample, to improve power. Since we focused on the role of knowledge about spoken language on vocabulary development, future research could include assessments of other precursors to vocabulary, e.g., home literacy and story-telling), in order to offer a complete assessment of lexical development.

The current study showed that the ability to learn phonologically similar new words is predictive of word knowledge above and beyond vocabulary size. Phonological skills in word learning thus appear to help with learning about the meanings of words. 


\section{References}

Anderson, R. C., \& Freebody, P. (1981). Vocabulary knowledge. In J. T. Guthrie (Ed.), Comprehension and teaching: research reviews (pp. 77-117). Newark, DE: International Reading Association.

Beck, I., McKeown, M. G., \& Kucan, L. (2002). Bringing words to life: robust vocabulary development. New York: Guilford.

Beckman, M. E., Munson, B., \& Edwards, J. (2007). Vocabulary growth and the developmental expansion of types of phonological knowledge. Laboratory Phonology 9, 241-64.

Biemiller, A. (2006). Vocabulary development and instruction: a prerequisite for school learning. In D. K. Dickinson \& S. B. Neuman (Eds.), Handbook of early literacy research, vol. 2 (pp. 41-51). New York/London: Guilford.

Biemiller, A., \& Slonim, N. (2001). Estimating root word vocabulary growth in normative and advantaged populations: evidence for a common sequence of vocabulary acquisition. Journal of Educational Psychology 93(3), 498-520.

Bowey, J. A., \& Patel, R. K. (1988). Metalinguistic ability and early reading achievement. Applied Psycholinguistics 9(4), 367-83.

Chaney, C. (1992). Language development, metalinguistic skills, and print awareness in 3-year-old children. Applied Psycholinguistics 13, 485-514.

Ehri, L. C. (2005). Learning to read words: theory, findings, and issues. Scientific Studies of Reading 9(2), $167-88$.

Elbro, C., Borstrøm, I., \& Petersen, D. K. (1998). Predicting dyslexia from kindergarten: the importance of distinctness of phonological representations of lexical items. Reading Research Quarterly 33(1), 36-60.

Elbro, C., Nielsen, I., \& Petersen, D. K. (1994). Dyslexia in adults: evidence for deficits in non-word reading and in the phonological representation of lexical items. Annals of Dyslexia 44(1), 203-26.

Graves, M. F. (1987). The roles of instruction in fostering vocabulary. In M. G. McKeown \& M. E. Curtis (Eds.), The nature of vocabulary acquisition (pp. 165-84). New York/London: Psychology Press.

Hart, B., \& Risley, T. R. (1995). Meaningful differences in the everyday experience of young American children. Baltimore, MD: Brookes.

Hulme, C., \& Snowling, M. J. (2009). Developmental disorders of language learning and cognition. Chichester/Malden, MA: John Wiley \& Sons.

Janssen, C., Segers, E., McQueen, J. M., \& Verhoeven, L. (2015). Lexical specificity training effects in second language learners. Language Learning 65(2), 358-89.

Junge, C., \& Cutler, A. (2014). Early word recognition and later language skills. Brain Sciences 4, 532-59.

Kooijman, V., Junge, C., Johnson, E. K., Hagoort, P., \& Cutler, A. (2013). Predictive brain signals of linguistic development. Frontiers in Psychology 4, 1-13.

Lonigan, C. J., Burgess, S. R., \& Anthony, J. L. (2000). Development of emergent literacy and early reading skills in preschool children: evidence from a latent-variable longitudinal study. Developmental Psychology 36(5), 596-613.

Metsala, J. L. (1999). Young children's phonological awareness and nonword repetition as a function of vocabulary development. Journal of Educational Psychology 91(1), 3-19.

Metsala, J. L., \& Walley, A. C. (1998). Spoken vocabulary growth and the segmental restructuring of lexical representations: precursors to phonemic awareness and early reading ability. In J. L. Metsala \& L. C. Ehri (Eds.), Word recognition in beginning literacy (pp. 89-120). Mahwah, NJ: Lawrence Erlbaum Associates.

Mulder, F., Timman, Y., \& Verhallen, S. (2009). Handreiking bij de Basiswoordenlijst Amsterdamse Kleuters (BAK). ITTA.

Munson, B., Edwards, J., \& Beckman, M. E. (2011). Phonological representations in language acquisition: climbing the ladder of abstraction. In A. C. Cohn, C. Fougeron, \& M. K. Huffman (Eds.), The Oxford handbook of laboratory phonology (pp. 288-309). Oxford University Press.

Nagy, W. E., \& Scott, J. A. (2000). Vocabulary processes. In M. L. Kamil, P. B. Mosenbach, P. D. Pearson, \& R. Barr (Eds.), Handbook of reading research, vol. III (pp. 269-84). Mahwah, NJ: Erlbaum.

Newman, R., Ratner, N. B., Jusczyk, A. M., Jusczyk, P. W., \& Dow, K. A. (2006). Infants' early ability to segment the conversational speech signal predicts later language development: a retrospective analysis. Developmental Psychology 42(4), 643-55.

Ouellette, G. P. (2006). What's meaning got to do with it: the role of vocabulary in word reading and reading comprehension. Journal of Educational Psychology 98(3), 554-66. 
Perfetti, C., \& Hart, L. (2002). The lexical quality hypothesis. In L. Verhoeven, C. Elbro, \& P. Reitsma (Eds.), Precursors of functional literacy (pp. 189-213). Amsterdam/Philadelphia: John Benjamins.

Read, J. (2004). Plumbing the depths: How should the construct of vocabulary knowledge be defined? In P. Bogaards \& B. Laufer (Eds.), Vocabulary in a second language: selection, acquisition, and testing (pp. 209-27). Amsterdam: John Benjamins.

Scarborough, H. (2005). Developmental relationships between language and reading: reconciling a beautiful hypothesis with some ugly facts. In H. W. Catts \& A. G. Kamhi (Eds.), The connections between language and reading disabilities (pp. 3-24). Mahwah, NJ: Erlbaum.

Schmitt, N. (2014). Size and depth of vocabulary knowledge: what the research shows. Language Learning 64(4), 913-51.

Schwanenflugel, P. J., Stahl, S. A., \& McFalls, E. L. (1997). Partial word knowledge and vocabulary growth during reading comprehension. Journal of Literacy Research 29(4), 531-53.

Serniclaes, W., Van Heghe, S., Mousty, P., Carré, R., \& Sprenger-Charolles, L. (2004). Allophonic mode of speech perception in dyslexia. Journal of Experimental Child Psychology 87(4), 336-61.

Stoel-Gammon, C. (2011). Relationships between lexical and phonological development in young children. Journal of Child Language 38(1), 1-34.

Storch, S. A., \& Whitehurst, G. J. (2002). Oral language and code-related precursors to reading: evidence from a longitudinal structural model. Developmental Psychology 38(6), 934-47.

Swan, D., \& Goswami, U. (1997). Phonological awareness deficits in developmental dyslexia and the Phonological Representations Hypothesis. Journal of Experimental Child Psychology 66, 18-41.

van Goch, M. M., McQueen, J. M., \& Verhoeven, L. (2014). Learning phonologically specific new words fosters rhyme awareness in Dutch preliterate children. Scientific Studies of Reading 18(3), 155-72.

van Goch, M. M., Verhoeven, L., \& McQueen, J. M. (2017). Trainability in lexical specificity mediates between short-term memory and both vocabulary and rhyme awareness. Learning and Individual Differences 57, 163-9.

Verhoeven, L. (2005). Screeningstest voor Taal- en Leesproblemen [Diagnostic Test for Language and Literacy Problems]. Arnhem: Cito.

Verhoeven, L., Reitsma, P., \& Siegel, L. S. (2011). Cognitive and linguistic factors in reading acquisition. Reading and Writing 24(4), 387-94.

Verhoeven, L., Van Leeuwe, J., \& Vermeer, A. (2011). Vocabulary growth and reading development across the elementary school years. Scientific Studies of Reading 15(1), 8-25.

Verhoeven, L., \& Vermeer, A. (2006). Taaltoets Alle Kinderen. Handleiding [Language test for children]. Arnhem: Cito.

Vermeer, A. (2001). Breadth and depth of vocabulary in relation to L1/L2 acquisition and frequency of input. Applied Psycholinguistics 22(2), 217-34.

Vloedgraven, J. M. T., Keuning, J., \& Verhoeven, L. (2009). Screeningsinstrument Beginnende Geletterdheid [Diagnostic instrument for emerging literacy]. Arnhem: Cito.

Wagner, R. K., Torgesen, J. K., \& Rashotte, C. A. (1994). Development of reading-related phonological processing abilities: new evidence of bidirectional causality from a latent variable longitudinal study. Developmental Psychology 30(1), 73-87.

Cite this article: van Goch MM, Verhoeven L, McQueen JM (2019). Success in learning similar-sounding words predicts vocabulary depth above and beyond vocabulary breadth. Journal of Child Language 46, 184-197. https://doi.org/10.1017/S0305000918000338 